\title{
Study of Behavior of Sesame (Sesamum Indicum L.) to Relative Turgidity, Diffusion Pressure Deficit and Transpiration Intensity under Arid Conditions of Western Rajasthan
}

\author{
Pankaj Swami (Corresponding author) \\ Plant Ecology Laboratory, Govt. Dungar College \\ Maharaja Ganga Singh University, PO box 334001 \\ Chokunti Gajner Road Bikaner. Rajasthan, India \\ Tel: 151-252-7777, 946-089-3777 E-mail: pankajswami00@gmail.com
}

\author{
Shamindra Saxena \\ Plant Ecology Laboratory, Govt. Dungar College \\ Maharaja Ganga Singh University, PO box 334001 \\ I-E-205 Vyas Colony Bikaner, Rajasthan, India
}

Tel: 946-000-0925 E-mail: saxenashamindra3@gmail.com

\author{
Suman Lata Tripathi \\ Plant Ecology Laboratory, Govt. Dungar College \\ Maharaja Ganga Singh University, PO box 334001 \\ 5C-43 J.N.V Colony Bikaner,Rajasthan India
}

Tel: 941-388-8277Ｅ-mail: suman_bikaner@yahoo.co.in

\begin{abstract}
A field experiment was conducted during kharif season of 2008 and 2009 (from august to october) to investigate the behavior of crop plant Sesame (Sesamum indicum L.) to RT (Relative turgidity), DPD (Diffusion pressure deficit) and TI (Transpiration intensity). The plant species (Sesamum indicum L.) investigated has been found to behave differentially with respect to relative turgidity, Diffusion pressure deficit and Transpiration intensity during different hours of day and at different stages Viz. Vegetative, flowering and capsule stage.
\end{abstract}

Keywords: Relative turgidity, Diffusion pressure deficit and Transpiration intensity

\section{Introduction}

In nature and even in agriculture, it is rare and fortunate that plant enjoys an optimum supply of water throughout its life. If we are concerned with the process controlling the growth with the world-wide problem of agriculture, than we must recognize that there is perhaps no single factor that is more crucial and none more amenable to an intervention than that of control over transpiration in plants. The most important aspect of plant water relationship is the internal water balance or degree of water stress because this controls the physiological and biochemical process and conditions which determine the quantity and quality of plant growth.

The water balance of plant is favorable as long as its transpiration and water absorption is equal. If the water losses exceed the absorption, the balance becomes negative. The plants have several means of recovering a good water balance or avoiding an increase of water absorption or reducing water loss through reduction of transpiring surface. The last possibility is frequently used for plants because it is effective very quickly.

Leaf water content data have been used for many years to provide an index of internal water deficit. The quantitative significance of relative turgidity has been enhanced by the demonstration that it is closely related to tissue water potential (Slatyer, 1960). This relationship is of value in that it can enable approximate estimates of water potential to be made from relative turgidity measurements. Transpiration, stomatal aperture, amount of water in leaves and osmotic value are popular indices which reflect the ability of plants to take up water under the prevailing atmospheric and edaphic conditions. However, they do not suggest that the water balance of 
different plants growing together comes to be different (Jarvis, 1967). It has been argued that transpiration alone gives little indication of the water balance of the plants. Sesame (Sesamum indicum L.), an important oil yielding plant, has yet not received due attention from this point of view; Consequently, the present study has been designed to know about its physiological aspects that is its relative turgidity, diffusion pressure deficit and transpiration intensity.

\section{Material and Methods}

A study was conducted during kharif seasons (from august to october) of 2008 and 2009 at crop field of Kodemdesar village of district Bikaner (Rajasthan, India) to study the behavior of crop plant (Sesamum indicum L.) with respect to RT, DPD and TI. For these purpose four varieties of sesame viz.RT-46( $\left.\mathrm{V}_{1}\right)$, RT-127( $\left.\mathrm{V}_{2}\right)$, RT-125 $\left(\mathrm{V}_{3}\right)$ and Local $\left(\mathrm{V}_{4}\right)$ were taken for investigation. The observations were taken mostly in the early hours of the morning because at this time the plants had complete night to absorb water and redistribute it internally and a plant-soil-water equilibrium normally existed.

\subsection{Estimation of relative turgidity}

Relative turgidity estimates involved the measurement of fresh weight, turgid weight and dry weight of tissue which were sampled. The plant samples were collected in polythene bag from the crop-ecosystem. To minimize the variability, as far as possible, the leaves were taken from the same position. Duplicate leaf segments (discs) were weighed (FW) immediately on the torsion balance. The discs were then floated on distilled water with under-side uppermost, in closed Petri dishes for 4 hours under most constant illumination at compensation point (Floating disc method). A constant temperature of $25^{\circ} \mathrm{C}$ maintained during this period. The discs were then drained and surface dried between eight sheets of blotting paper for 5 seconds under a weight of $500 \mathrm{~g}$ (Hellmuth, 1970). The discs were weighed immediately on torosion balance to get turgid weight (TW). After determining turgid weight the samples' were oven dried at $80^{\circ} \mathrm{C}$ for 24 hours to constant weight and weighed. This gives the dry weight (DW) of samples. Relative turgidity in percentage was calculated by Weatherley formula (1950).

$$
R T=\frac{F W-D W}{T W-D W}
$$

\subsection{Estimation of Diffusion pressure deficit}

Diffusion pressure deficit was determined with the help of Erma Abbe refractometer. Crop samples were transferred to sugar solutions of different osmotic concentrations and after allowing sufficient time (6 hours) for equilibration, the refractive indices of the solutions in which the samples were kept, were determined by direct reading in refractometer. The mean of two seasons and each of five replications have been presented in table 1.

The procedure consists of a series of test tubes which were filled with $1 \mathrm{ml}$ (in each test tube) of sucrose solutions of various osmotic concentrations covering the range in water potential likely to be encountered in the crop tissues under study. Optimum amount of plant tissues were placed in each tube to fill it to the level of liquid. Approximately 3 leaf discs of $1 \mathrm{~cm}$ diameter for each tube were found adequate. A series of control solutions were set up which were identical except that they were without plant tissues. After allowing sufficient time for equilibration, the refractive indices of the solutions in which the samples were kept and control were determined directly by refractometer. After comparing the values of control and test solutions, diffusion pressure deficit was estimated as the osmotic pressure of that solution in which the plant samples showed either no change or the least change in the refractive index.

\subsection{Estimation of Transpiration intensity}

Huber's method as given by Maximov (1929) was followed for determining the transpiration intensity. The method consisted of rapid weighing of the plant material (leaves) on torsion balance. Detached leaves were exposed for a minute's period after detachment and the final weight taken after one minute gave the loss of water per minute. The loss of water was then expressed as transpiration in $\mathrm{mg} / \mathrm{g} / \mathrm{h}$. Gaballah et al (2007) applied antitranspirant maters on two sesame cultivars named Gize 32 and Shanavil 3 and observed that preventing water transpiration from leaves led to increase in Relative water content in these cultivars. Langham et al (2008) pointed out that there is a high positive correlation between yield and total light units in the vegetative and reproductive phases.

\section{Results and Discussion}

The relative turgidity percent shows no significant varietal difference. The maximum turgidity percent has been in $\mathrm{V}_{1}$ and followed by $\mathrm{V}_{3}, \mathrm{~V}_{4}$ and $\mathrm{V}_{2}$ at the vegetative growth stage. The minimum value of relative turgidity percent has been shown by $V_{2}$. A descending trend has been noticed in relative turgidity values from vegetative 
to flowering and from flowering to capsule stages respectively. Concurrently, with decline in relative turgidity values an increase in diffusion pressure deficit has been noticed (Table 1, fig 1\& 2). The diffusion pressure deficit values show no varietal differences at any of the growth stage, where as relative turgidity values decreased subsequently. An ascending trend in diffusion pressure deficit values has been noticed from vegetative growth stage to capsule stage. It may be due to increased water stress coupled with ageing and agro-climate, because late rains were very poor or not at all.

The diurnal variations in transpiration intensity have been shown in table $2 \& 3$. The maximum transpiration intensity has been at $11 \mathrm{hrs}$ and 14 hours. The minimum value of transpiration had been at 18 hours, when relative humidity percentage $(\% \mathrm{RH})$ also has minimum value. The transpiration intensity allowed a general increase during the day hours and it declined towards evening. The highest transpiration intensity has been shown by $\mathrm{V}_{3}$ (RT 125) and lowest $\mathrm{V}_{4}$ (Local). At 12 hours and 13 hours the transpiration intensity was low despite of high light intensity. It might be due to closure of stomata at high light intensity. This suggests that in sesame transpiration intensity is directly related to seed productivity acting as indicator for selection. Mensah et al (2006) also suggested that prolonged osmotic tension resulted in stunted growth, reduced dry matter, number of leaves per plant and seed yield per plant.

\section{References}

Gaballah, M.S., Abou Leila, B., El-Zeiny, H.A. and Khalil, S. (2007). Estimating the performance of salt-stressed sesame plant treated with antitranspirants. J. Applied Sci. Res., 3: 811-817.

Helimuth, O. Erhart. (1970). Measurement of leaf water deficit with particular reference to the whole leaf method. J. Ecol., 58: 409-417.

Huber, W., Sankhala, N., Ziegler, H. (1973). Eco-physiological studies on Indian arid zone plants I. photosynthetic characterstics of pennisetum typhoides (Burm. F. \& Hubbard and Lasirus sindicus Henr. Oecologia (Berl.) 13, 65-71.

Jarvis, P.G. (1967). Comparative plant water relation. Annals of Arid Zone, 6: 74-88.

Langham, D.R., Riney, J., Smith, G., \& Wiemers T. (2008). Sesame Grower Guide, Sesaco Corporation, San Antonio, TX.

Maximov, N.A. (1929). The plant in relation to water. Allen \& Uncoin, London.

Mensah, J.K., Obadoni, B.O., Eroutor, P.G. and Onome-Irieguna, F. (2006). Simulated flooding and drought effects on germination, growth, and yield parameters of Sesame (Sesamum indicum L.). Afr. J. Biotechnol., 5: 1249-1253.

Slatyer, R.G. (1960). Absorption of water by plant. Bot. Rev. 26:331-392.

Weatherley, P.E. (1950). Studies in water relations of the cotton plant. I. The field measurement of water deficits in leaves. New. Phytol. 49: 81-97.

Table 1. Relative turgidity (RT \%) and diffusion pressure deficit (DPD) of Sesamum indicum L

\begin{tabular}{|c|c|c|c|c|c|c|c|}
\hline S. NO. & \multirow{2}{*}{ VARIETIES } & \multicolumn{2}{|c|}{$\begin{array}{c}\text { VEGETATIVE } \\
\text { GROWTH STAGE }\end{array}$} & \multicolumn{2}{|c|}{$\begin{array}{c}\text { FLOWERING } \\
\text { STAGE }\end{array}$} & \multicolumn{2}{|c|}{$\begin{array}{c}\text { CAPSULE } \\
\text { STAGE }\end{array}$} \\
\hline & & $\mathrm{RT}$ & $\mathrm{DPD}$ & $\mathrm{RT}$ & $\mathrm{DPD}$ & $\mathrm{RT}$ & DPD \\
\hline 1. & $\mathrm{~V}_{1}$ & 90.2 & 3.2 & 77.8 & 9.1 & 73.2 & 14.3 \\
\hline 2. & $\mathrm{~V}_{2}$ & 89.6 & 3.2 & 77.2 & 9.1 & 73.0 & 14.3 \\
\hline 3. & $\mathrm{~V}_{3}$ & 89.8 & 3.2 & 78.6 & 9.1 & 74.6 & 14.3 \\
\hline 4. & $\mathrm{~V}_{4}$ & 89.2 & 3.2 & 76.2 & 9.1 & 73.2 & 14.3 \\
\hline
\end{tabular}

DPD as molar concentration of sucrose. Mean of five replications. 
Table 2. Transpiration intensity in mg.g-1 hr-1

\begin{tabular}{|c|c|c|c|c|c|c|c|c|}
\hline \multirow{2}{*}{ Variety } & \multicolumn{9}{|c|}{ Time of day } & \\
\hline & & & & & & \\
& $6 \mathrm{hrs}$ & $7 \mathrm{hrs}$ & $8 \mathrm{hrs}$ & $9 \mathrm{hrs}$ & $11 \mathrm{hrs}$ & $10 \mathrm{hrs}$ & $12 \mathrm{hrs}$ & $13 \mathrm{hrs}$ \\
\hline $\mathrm{V}_{1}$ & 0 & 230 & 680 & 800 & 800 & 1620 & 930 & 660 \\
\hline $\mathrm{V}_{2}$ & 0 & 650 & 180 & 1420 & 1310 & 1160 & 1070 & 470 \\
\hline $\mathrm{V}_{3}$ & 0 & 470 & 890 & 1160 & 1210 & 1730 & 1700 & 650 \\
\hline $\mathrm{V}_{4}$ & 0 & 430 & 650 & 780 & 780 & 1270 & 890 & 600 \\
\hline$\% \mathrm{RH}$ & & 90 & 85 & 100 & 70 & 70 & 100 & 60 \\
\hline
\end{tabular}

Table 3. Transpiration intensity in mg.g-1 hr-1

\begin{tabular}{|c|c|c|c|c|c|c|c|}
\hline Variety & \multicolumn{7}{|c|}{ Time of day } \\
\hline & $14 \mathrm{hrs}$ & $15 \mathrm{hrs}$ & $16 \mathrm{hrs}$ & $17 \mathrm{hrs}$ & $18 \mathrm{hrs}$ & $19 \mathrm{hrs}$ & Mean \\
\hline $\mathrm{V}_{1}$ & 1650 & 650 & 550 & 420 & 150 & 0 & 761.166 \\
\hline $\mathrm{V}_{2}$ & 1470 & 870 & 690 & 450 & 210 & 0 & 912.5 \\
\hline $\mathrm{V}_{3}$ & 1490 & 1190 & 1130 & 420 & 180 & 0 & 1018.333 \\
\hline $\mathrm{V}_{4}$ & 1320 & 620 & 530 & 380 & 140 & 0 & 699.166 \\
\hline$\%$ RH & 55 & 50 & 57 & 56 & 56 & - & - \\
\hline
\end{tabular}




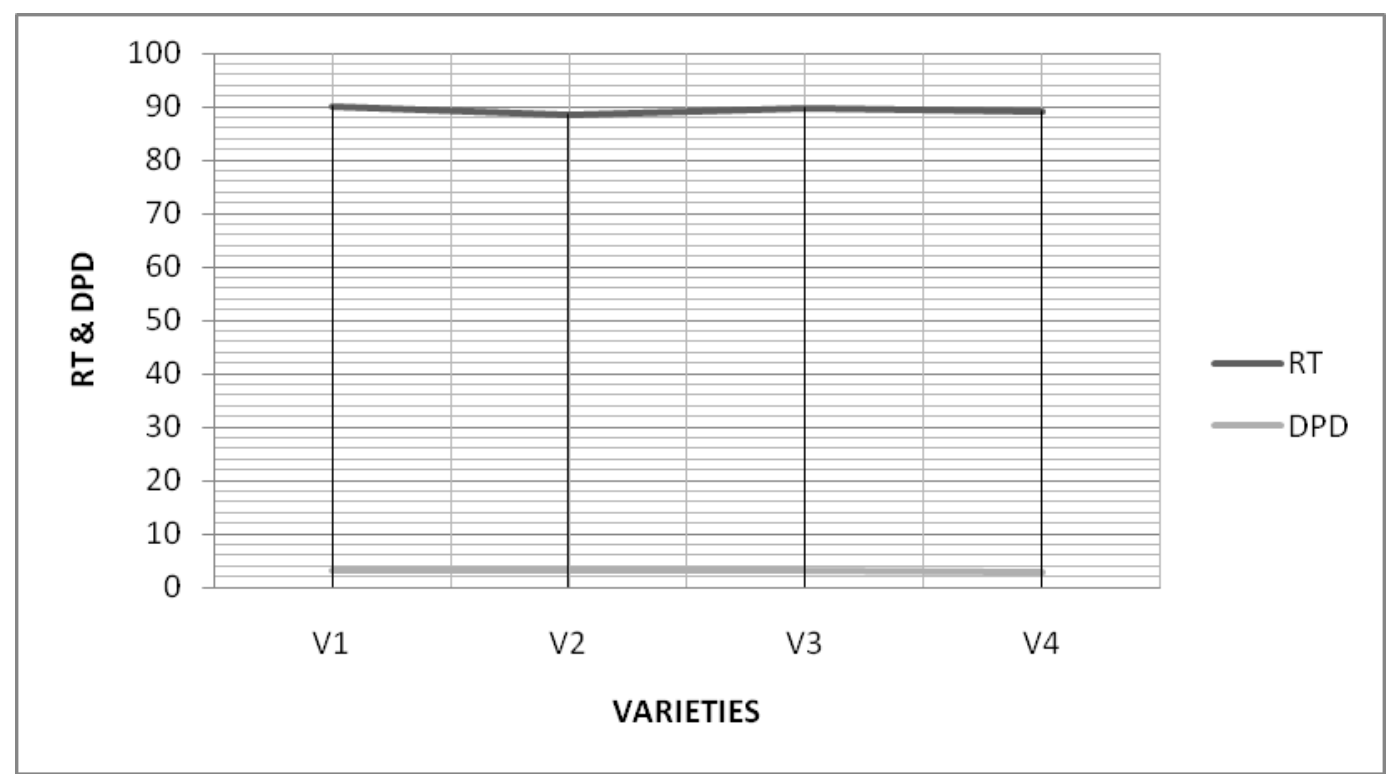

Figure 1.

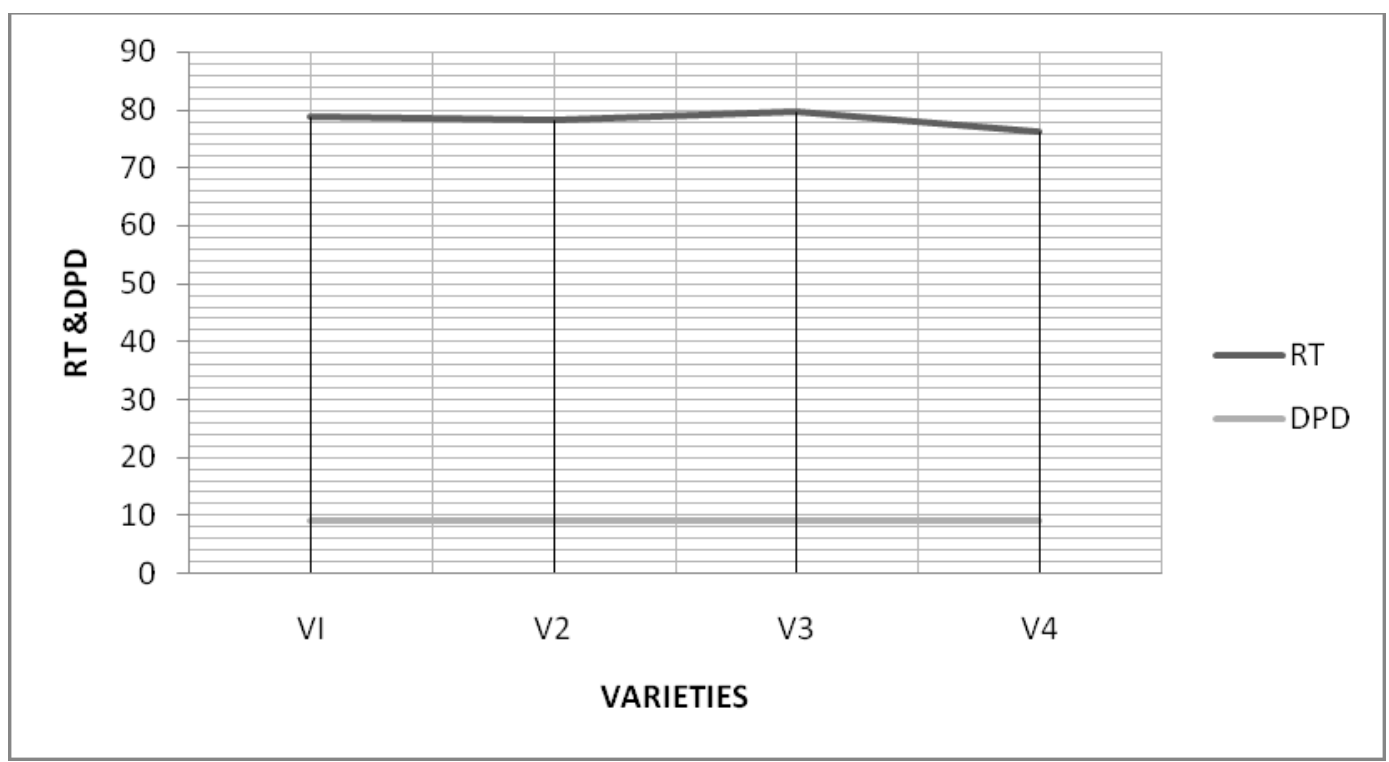

Figure 2.

Figure $1 \& 2$. Showing relationship between RT\&DPD with varieties of sesame at vegetative and flowering stage 


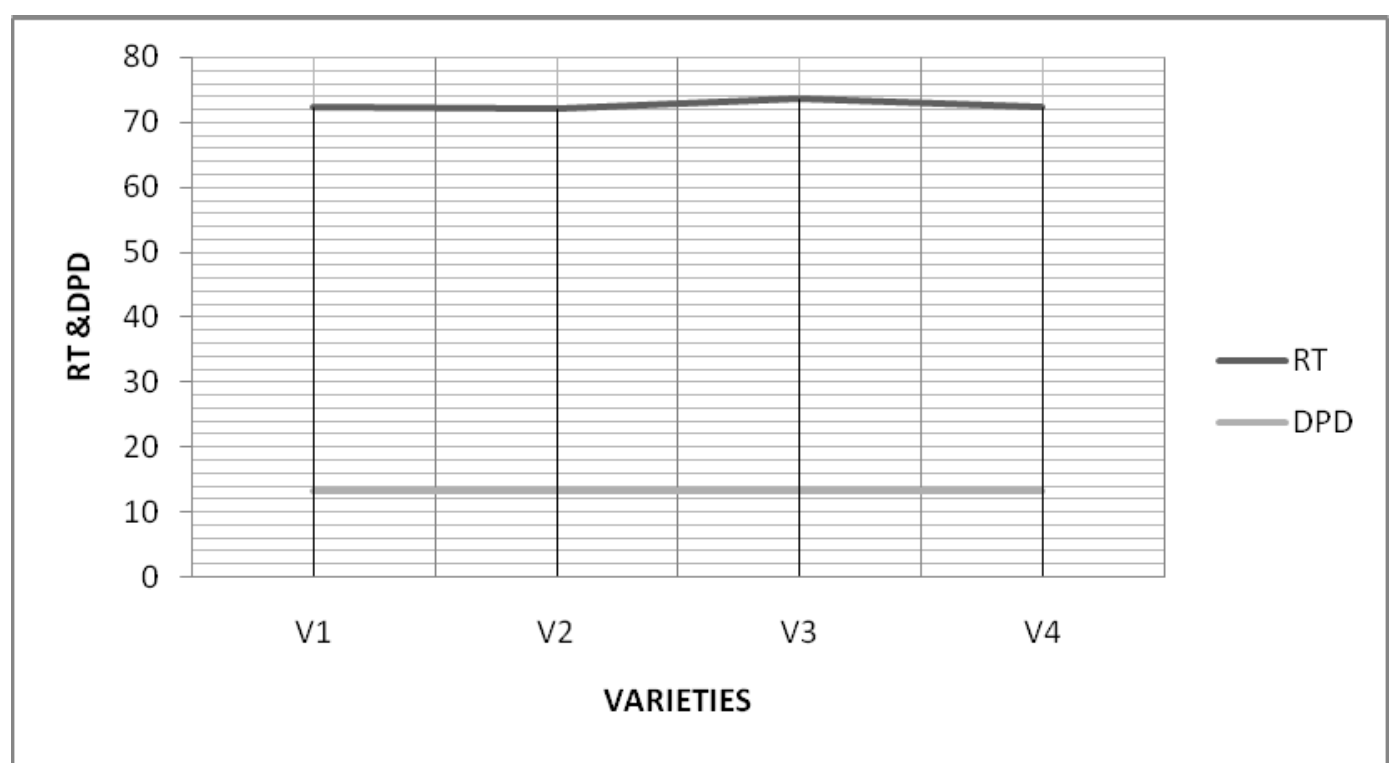

Figure 3. Showing relationship between RT\&DPD with varieties of sesame at capsule stage 